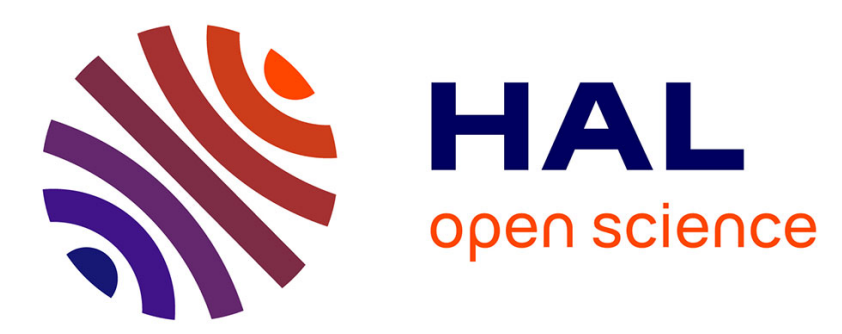

\title{
Structural mechanical testing of a full-size adhesively bonded motorboat
}

P. Baur, A. Roy, Pascal Casari, Dominique Choqueuse, Peter Davies

\section{To cite this version:}

P. Baur, A. Roy, Pascal Casari, Dominique Choqueuse, Peter Davies. Structural mechanical testing of a full-size adhesively bonded motorboat. Proceedings of the Institution of Mechanical Engineers, Part M: Journal of Engineering for the Maritime Environment, 2004, 218 (4), pp.259-265. 10.1177/147509020421800405. hal-01007334

\section{HAL Id: hal-01007334 \\ https://hal.science/hal-01007334}

Submitted on 29 Nov 2017

HAL is a multi-disciplinary open access archive for the deposit and dissemination of scientific research documents, whether they are published or not. The documents may come from teaching and research institutions in France or abroad, or from public or private research centers.
L'archive ouverte pluridisciplinaire HAL, est destinée au dépôt et à la diffusion de documents scientifiques de niveau recherche, publiés ou non, émanant des établissements d'enseignement et de recherche français ou étrangers, des laboratoires publics ou privés. 


\title{
Structural mechanical testing of a full-size adhesively bonded motorboat
}

\author{
P Baur ${ }^{1}$, A Roy ${ }^{1}$, P Casari ${ }^{2}$, D Choqueuse ${ }^{3}$ and P Davies ${ }^{3 *}$ \\ ${ }^{1}$ CRITT Matériaux, Rochefort Cedex, France \\ ${ }^{2}$ Institut de Recherche en Génie Civil et Mécanique, Université de Nantes, France \\ ${ }^{3}$ Materials and Structures group, IFREMER Brest Centre, Plouzané, France
}

\begin{abstract}
This paper describes the tests performed on a full-size motorboat to demonstrate the potential for adhesive bonding to replace overlaminated connections. Adhesive bonding resulted in a significant reduction in assembly time for bulkhead connections compared with overlamination. Drop tests and sea trials were performed using specially adapted strain gauge instrumentation. These indicated low adhesive joint strain levels, even for severe test conditions. No damage was observed. The data obtained will be used to improve laboratory test procedures to simulate service loading of boat structures.
\end{abstract}

Keywords: adhesive, structural testing, marine composites, impact, sea trials

\section{INTRODUCTION}

Composite materials have been extensively used in the pleasure boat industry for many years [1-3]. The manufacture of small pleasure boats (motorboats and sailing boats from about 5 to $8 \mathrm{~m}$ long) involves the assembly of different components, the main ones being the deckhull and bulkhead-hull connections. These operations are time consuming and can account for up to 30 per cent of the total manufacturing time. In order to reduce this time and the associated labour costs, the use of bonding is now being considered by some boatyards to replace the overlaminating method (which is currently widely used).

To validate this manufacturing option, a research programme including research centres, adhesive manufacturers and boatyards started several years ago. Many of the results from the initial studies, which focused on the mechanical behaviour and durability of adhesively bonded specimens, have been reported [4-7]. In parallel with tests carried out in the laboratory on subcomponents, an adhesively bonded prototype has been manufactured, instrumented and tested under real conditions. This paper will describe these prototype tests.

The aims of this part of the programme were as follows:

* Corresponding author: Materials and Structures group, IFREMER Brest Centre, 29280 Plouzané, France. (a) to improve the manufacturing process,

(b) to evaluate the loads applied to the connections at sea,

(c) to verify by a drop test the capability of the structure to support severe loading.

\section{MANUFACTURING OF THE PROTOTYPE}

The structure retained for this study is a $5.75 \mathrm{~m}$ long motorboat designed for sea fishing and excursions (Fig. 1a). The characteristics of the boat are shown in Table 1.

This boat is an improved standard boat, and the manufacturing process has been modified in order to replace the overlaminating of the bulkheads onto the hull structure by a bonding operation. Figure $1 \mathrm{~b}$ shows the interior of the boat before bonding the deck.

The adhesive chosen is a filled vinyl ester based adhesive provided by the Reichhold company. Other

Table 1 Prototype boat characteristics

\begin{tabular}{ll}
\hline Length & $5.75 \mathrm{~m}$ \\
Width & $2.45 \mathrm{~m}$ \\
Draught & $0.4 \mathrm{~m}$ \\
Weight without engine & $640 \mathrm{~kg}$ \\
Motor & $90 \mathrm{hp}$ \\
Maximum speed & $30 \mathrm{knots}$ \\
Hull and deck construction & Glass/polyester by hand lay-up \\
Bulkhead construction & $10 \mathrm{~mm}$ thick plywood \\
\hline
\end{tabular}




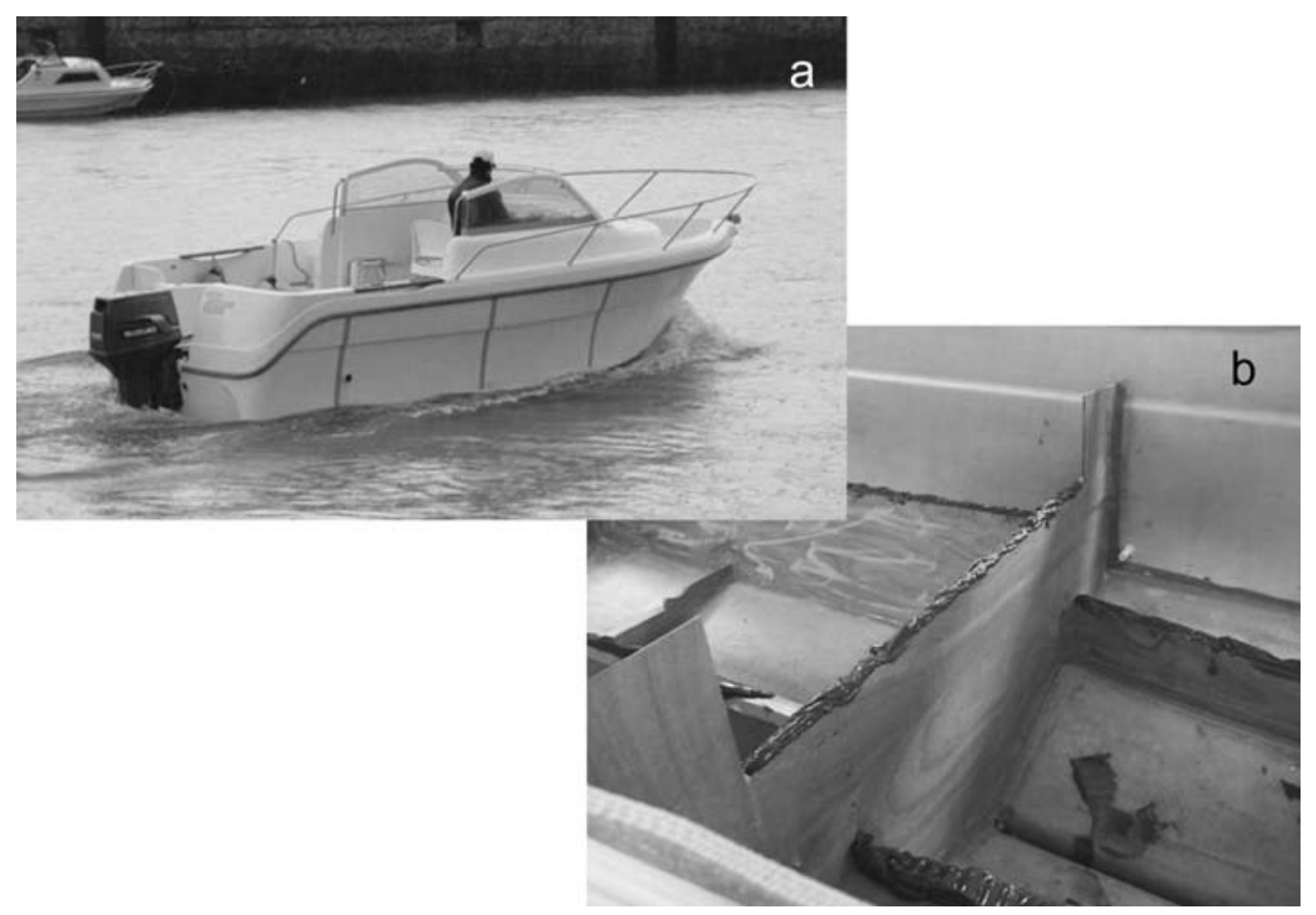

Fig. 1 (a) Prototype motorboat and (b) detail of the bulkhead-hull

structural adhesives including orthophthalic and isophthalic polyesters were also evaluated in a preliminary test programme [7], but this vinyl ester was retained on account of its superior long-term behaviour. It should be noted that epoxy-based adhesives were considered to be too expensive for this application. The adhesive is applied in a very simple way, and no surface preparation of either the GRP or the plywood was performed prior to bonding. The gap between the bulkhead and the hull varied from less than $1 \mathrm{~mm}$ up to over $10 \mathrm{~mm}$. Such variations are not unusual, but adhesive bondline thickness can have a strong influence on joint strength, and this was one of the parameters examined in the initial test programme. Figure 2 shows an example of results.

Influence of bondline thickness, composite/composite:

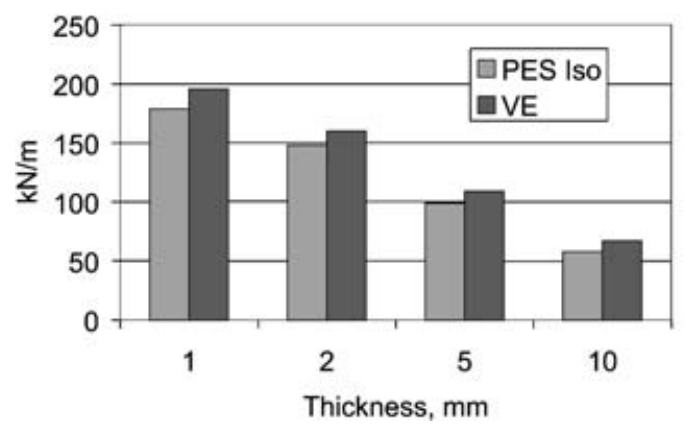

Fig. 2 Assembly strength versus bondline thickness, single-lap shear tests, two adhesives
The drop in measured failure load is related to an increase in peel loading as the bondline gets thicker. There may also be more defects in the thicker joints. Thus, apparent strengths of these adhesives do show a dependence on thickness, and when possible it is preferable to reduce bondline thickness, particularly in highly loaded regions.

For the bulkhead-hull assembly, the bulkheads were placed in position in the boat without fixing, and then a length of adhesive was applied on each side of the bulkhead and manually smoothed. The time needed for this operation is $45 \mathrm{~min}$, whereas the overlaminating operation requires $4 \mathrm{~h}$. For the bulkhead-deck assembly the adhesive was first deposited on the edge of the plywood, and then the deck was put in place without pressure.

In this first phase of the project the bonding process has only been applied to the assembly of the bulkhead with the hull and deck structure. The full bonding including the hull-deck connection will be considered at a later date.

\section{INSTRUMENTATION}

Few experiments have been performed to measure the strains during navigation of composite pleasure boats, though there is considerable experience of slamming pressures from tests on military craft $[\mathbf{8}]$. Baley and 
Cailler have described measurements made on an instrumented $7.7 \mathrm{~m}$ long prototype composite sailing boat [9], while Hentinen and Holm measured slamming loads on a $9.2 \mathrm{~m}$ yacht [10]. Choqueuse has measured strains on a large composite motor cruiser [11]. The anisotropy of the materials, the low strain values on running sections of the structure, the dynamics of the signal (acquisition rates of at least $500 \mathrm{~Hz}$ are needed), the limited knowledge of the real geometry (thickness, resin content, ply orientation, etc.) at a given point and the poor stability of strain gauge measurements on low heat dissipation materials (GRP) combine to make this type of measurement very difficult. Taking into account these parameters, and the aim of the study being to determine the loading of the bonded joint, a special instrumentation system was defined.

The load applied to motor boats differs from that applied to sailing vessels. For the latter the transfer of the wind loading by the mast and the rigging has to be considered, whereas for motor boats the transfer of the power generated by the engine (inboard or outboard) is of prime importance. For all vessels the load induced by slamming (repeated wave loading) has to be considered. However, for the motor boat considered in this study, in order to simplify the mechanical loading applied to the connections, they can be split into (Fig. 3): (a) tension-compression,

(b) bending,

(c) shear.

Three locations were retained for study, based on the boatbuilder's experience and discussions with a naval architect. These are regions in which joint damage had been observed after severe loading in service, and are shown in Fig. 4.

The measurements are made using sensors composed of strain gauge combinations, which are directly bonded to the adhesive joint of a bulkhead-hull connection. A full Wheatstone bridge is built (four $120 \mathrm{ohm}$ gauges) in order to increase the sensitivity, and the wiring is adapted in order to concentrate on the loading of interest. Thus, each instrumented connection allows the measurement of a particular response by eliminating the other responses. For example, for the tension-compression ( $\mathrm{T}-\mathrm{C}$ ) sensor, rosettes of $0-90^{\circ}$ gauges are placed on each side of the joint and the wiring is chosen in order to eliminate the bending and temperature effects (Fig. 5).

This sensor is located on the main central perpendicular bulkhead (Fig. 4). For the bending (B) sensor the same positioning of the gauges is performed, but the wiring differs in order to eliminate the tension-compression effect. For the shear $(\mathrm{S})$ sensor the gauges are placed at
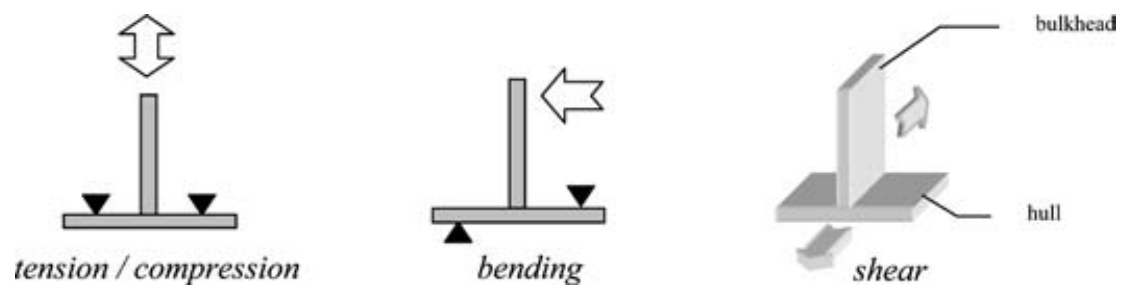

Fig. 3 Mechanical loads on motorboat joints

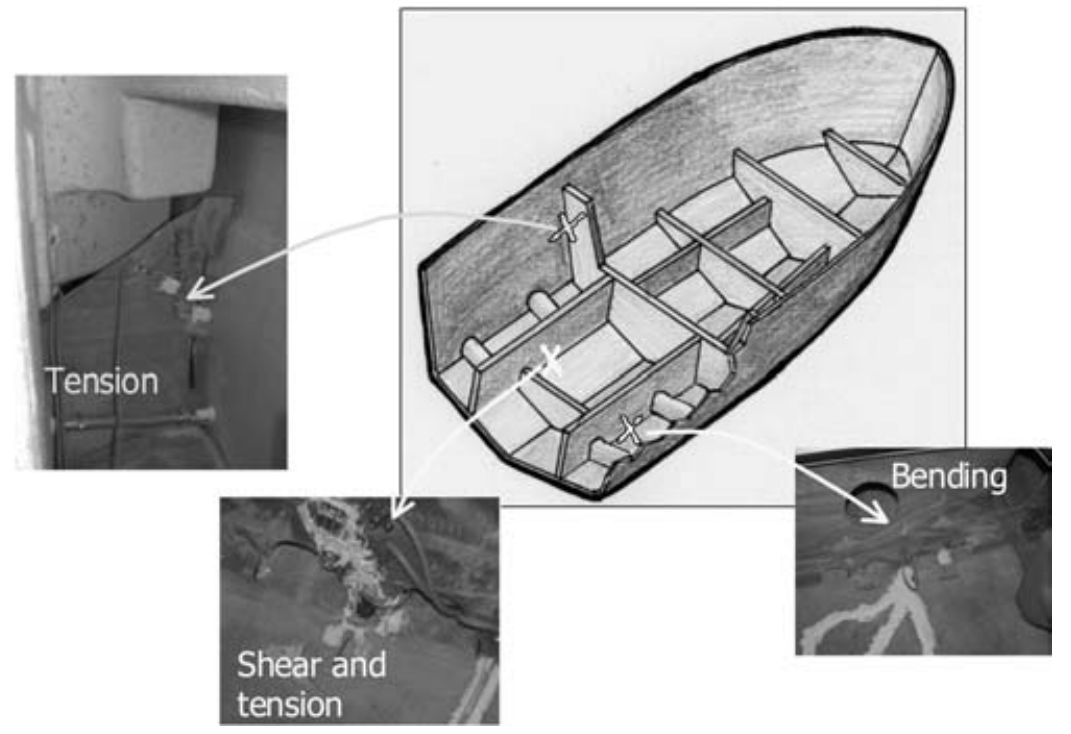

Fig. 4 Sensor positions 


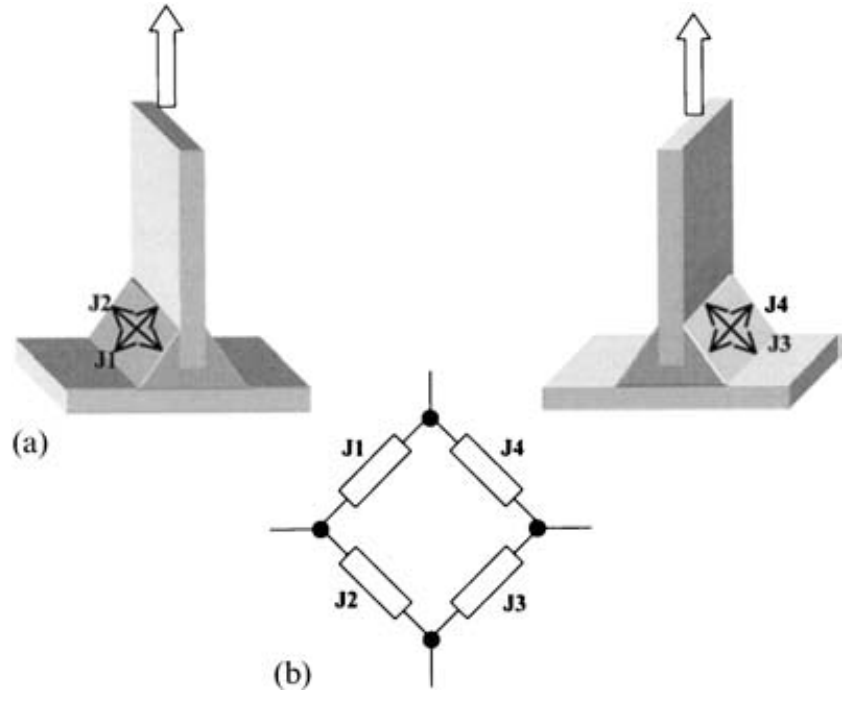

Fig. 5 Tension-compression sensor: (a) gauge positions; (b) wiring diagram. Plane strain assumption: $\varepsilon_{\mathrm{t}}=$ tension strain; $\varepsilon_{\mathrm{b}}=$ bending strain; $k=$ gauge factor; $\alpha \Delta t=$ response to temperature variation; $\mathrm{J} 1=k^{*}$ $\left(\varepsilon_{\mathrm{t}}+\varepsilon_{\mathrm{b}}\right)+\alpha \Delta t ; \quad \mathrm{J} 3=k^{*}\left(\varepsilon_{\mathrm{t}}-\varepsilon_{\mathrm{b}}\right)+\alpha \Delta t ; \quad \mathrm{J} 2=\alpha \Delta t ;$ $\mathrm{J} 4=\alpha \Delta t ; R=\mathrm{J} 1+\mathrm{J} 3-\mathrm{J} 2-\mathrm{J} 4>R=2 * k * \varepsilon_{\mathrm{t}}$

$45^{\circ}$ to the connection axis (Fig. 6). It should also be noted that the wiring of the shear sensors results in a sensitivity twice that of the other sensors.

The bending and shear sensors are placed symmetrically on the back of the two longitudinal bulkheads. An HBM Spider ${ }^{(m)}$ acquisition data system coupled to a portable computer is used to collect the data. Depending on the type of test, a 2 or $10 \mathrm{~s}$ data sequence is recorded. Data recording is triggered by a signal increase.

\section{DROP TEST}

The first type of test that was performed was a drop test. Similar tests have been used in the past at DNV to study

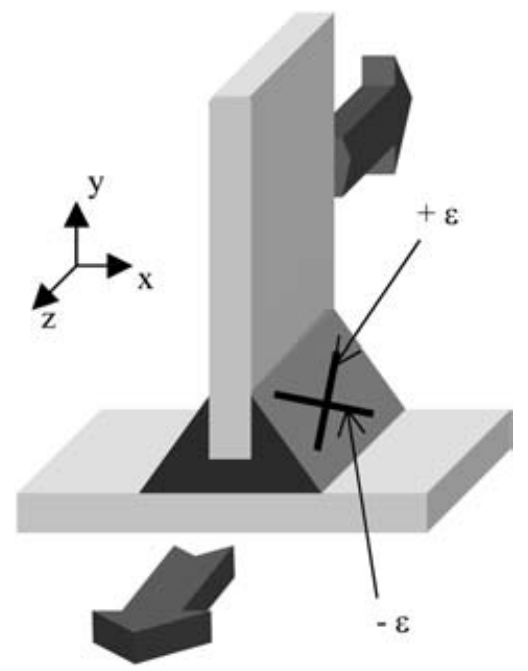

Fig. 6 Shear sensor the impact response of boat sections [12]. Here, the boat was lifted by a crane and dropped onto calm water in the $20 \mathrm{~m}$ deep section of the IFREMER test basin in Brest. Series of $2 \mathrm{~s}$ data recordings were made during the first phase of contact with the water. Figure 7 shows illustrations of the behaviour of the boat during the drop.

Different configurations have been retained for this test. They are reported in Table 2. For the fifth test the sandbags were distributed as follows: $120 \mathrm{~kg}$ at the engine position, $400 \mathrm{~kg}$ in the cockpit, $80 \mathrm{~kg}$ on the aft side of the boat. This distribution simulates the loads in navigation. Some examples of results are presented on the plots in Fig. 8.

The maximum value is obtained during the first $200 \mathrm{~ms}$ after the impact with the water, and then the signal is quickly damped to reach a value less than 10 per cent of the maximum value after less than $2 \mathrm{~s}$. A general vibration frequency is noted at about $3.5 \mathrm{~Hz}$ which probably corresponds to the first mode shape of the structure. The maximum values observed during the impacts are reported in Table 3. These values are discussed further below.

\section{SEA TRIALS}

The sea trials were performed in the Atlantic Ocean off the West coast of France. During navigation the boat was loaded with three passengers. The sea conditions were quite good (sea condition level 3-4) with a $30 \mathrm{~cm}$ high wave. The measurements were made at a maximum speed of 30 knots and for different vessel orientations with respect to the wave direction (meeting the wave direction head on, at $45^{\circ}$, and with the wave aft) in both straight-on navigation and during turns. Two examples of results are given in Fig. 9.

Table 2 Drop test conditions

\begin{tabular}{|c|c|}
\hline $\begin{array}{l}\text { Test } \\
\text { number }\end{array}$ & Test configuration \\
\hline 1 & Boat empty, $1 \mathrm{~m}$ drop, horizontal \\
\hline 2 & Boat empty, 2 m drop, horizontal \\
\hline 3 & $\begin{array}{l}\text { Boat empty, } 1 \mathrm{~m} \text { drop, on port side in order to increase } \\
\text { response of tension-compression and bending sensors }\end{array}$ \\
\hline 4 & Boat empty, $1 \mathrm{~m}$ drop, on starboard side \\
\hline 5 & Boat loaded with $600 \mathrm{~kg}$ by sandbag, $1 \mathrm{~m}$ drop, horizontal \\
\hline
\end{tabular}

Table 3 Maximum strains recorded during drop tests

\begin{tabular}{lcl}
\hline Sensor & $\begin{array}{l}\text { Maximum value } \\
\text { of } \Delta l / l(\%)\end{array}$ & $\begin{array}{l}\text { Drop test } \\
\text { number }\end{array}$ \\
\hline T-C & -0.27 & $3-5$ \\
B & 0.34 & $4-5$ \\
S & 0.06 & 3 \\
\hline
\end{tabular}




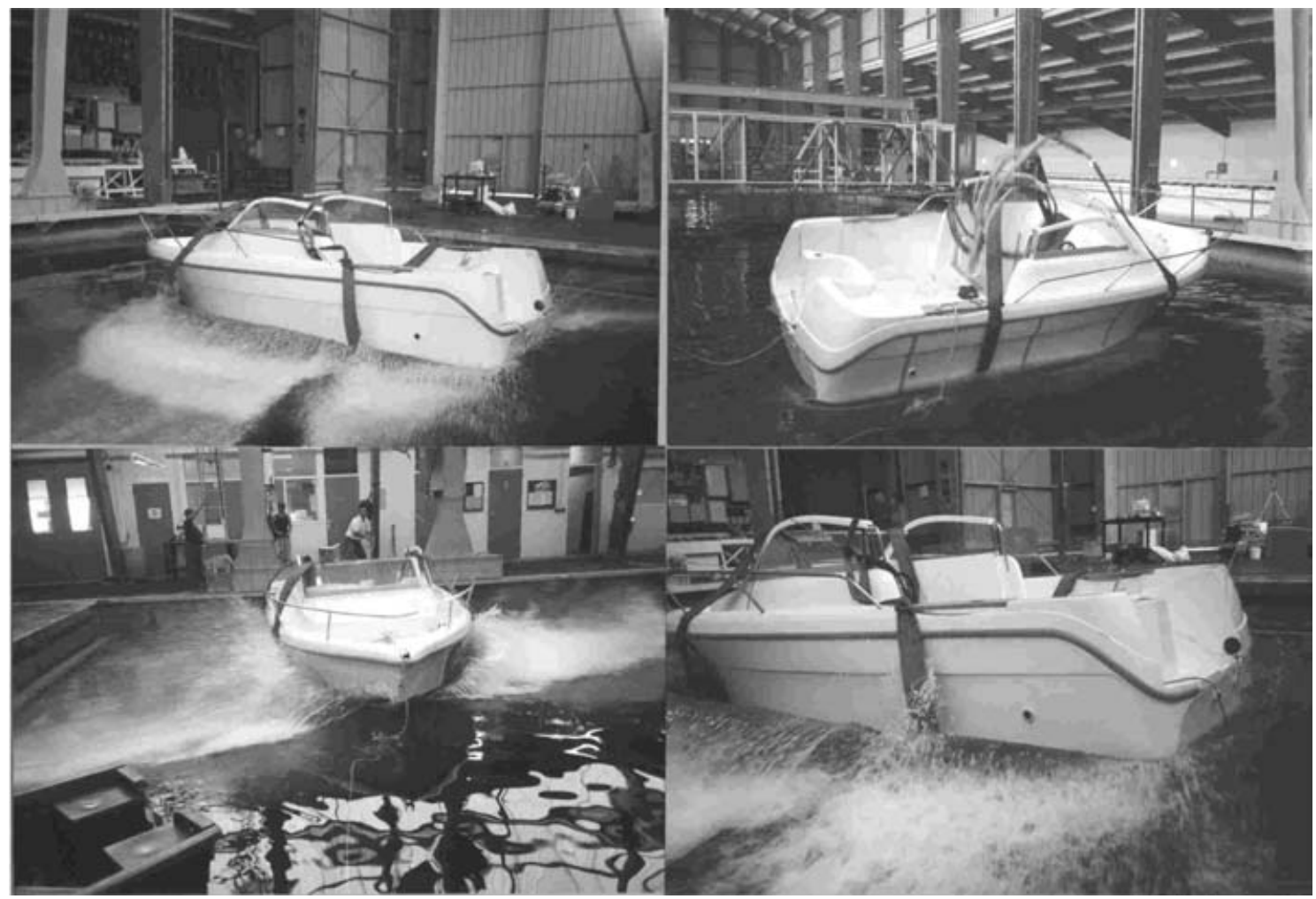

Fig. 7 Photos showing boat drop tests

On these curves a general periodic signal with a frequency of around $3-5 \mathrm{~Hz}$ is again noted. This frequency is in accordance with the signal observed during the drop test and can be attributed to a general mode shape of the structure.

The maximum values are observed for peaks which have a value 5 times higher than the general value observed during navigation. This peak level must occur at the moment when the boat motion is out of phase with the sea surface.

During tacking, a significant increase in signal is observed in the bending sensor. However, the level obtained appears to be much lower than the peak observed during the full-speed navigation. The maximum values observed on each sensor are reported in Table 4.

It is apparent that these values are considerably lower than the maximum values recorded in the drop tests. Their significance is discussed further below.

Table 4 Sea trial maximum values recorded

\begin{tabular}{llll}
\hline Sensor & $\begin{array}{l}\text { Maximum value } \\
\text { of signal } \\
(\mathrm{mV} / \mathrm{V})\end{array}$ & $\begin{array}{l}\text { Maximum } \\
\text { value of } \\
\Delta l / l(\%)\end{array}$ & Test \\
\hline $\mathrm{T}-\mathrm{C}$ & -1.2 & -0.12 & $+45^{\circ} /$ sea \\
$\mathrm{B}$ & 1.1 & 0.1 & $\begin{array}{l}\text { Facing the waves } \\
\mathrm{S}\end{array}$ \\
\hline
\end{tabular}

\section{DISCUSSION OF RESULTS}

The first point to highlight is that no damage has been observed on the boat after these two series of tests. This confirms the potential for adhesive bonding to manufacture the joints in motorboats of this type, though of course a final judgement will only be possible when information on long-term behaviour of the structure is available after many years of in-service navigation of the boat.

In order to establish how close the adhesive is to damage and failure, the values recorded by the sensors during the trials (Tables 3 and 4) should be related to the corresponding material properties. Unfortunately, this is not simple. The values of strain, $\Delta l / l$, in percentages, have been indicated in these tables. These values take into account the gauge factor and the type of bridge wiring. However, as the loading conditions cannot be clearly defined, and the joint geometry is not perfect (variable shape and symmetry), it is very hard to make this correlation, so the values noted must be considered as indicative only. In addition, the values provided by the sensors correspond to the surface strains of the joint. The strain within the joint is quite complex, as can be shown by a simple finite element analysis, and the value will strongly depend on the exact geometry. Modelling of the whole vessel with the detail necessary to study the hot spots, which are to be expected at the stress 

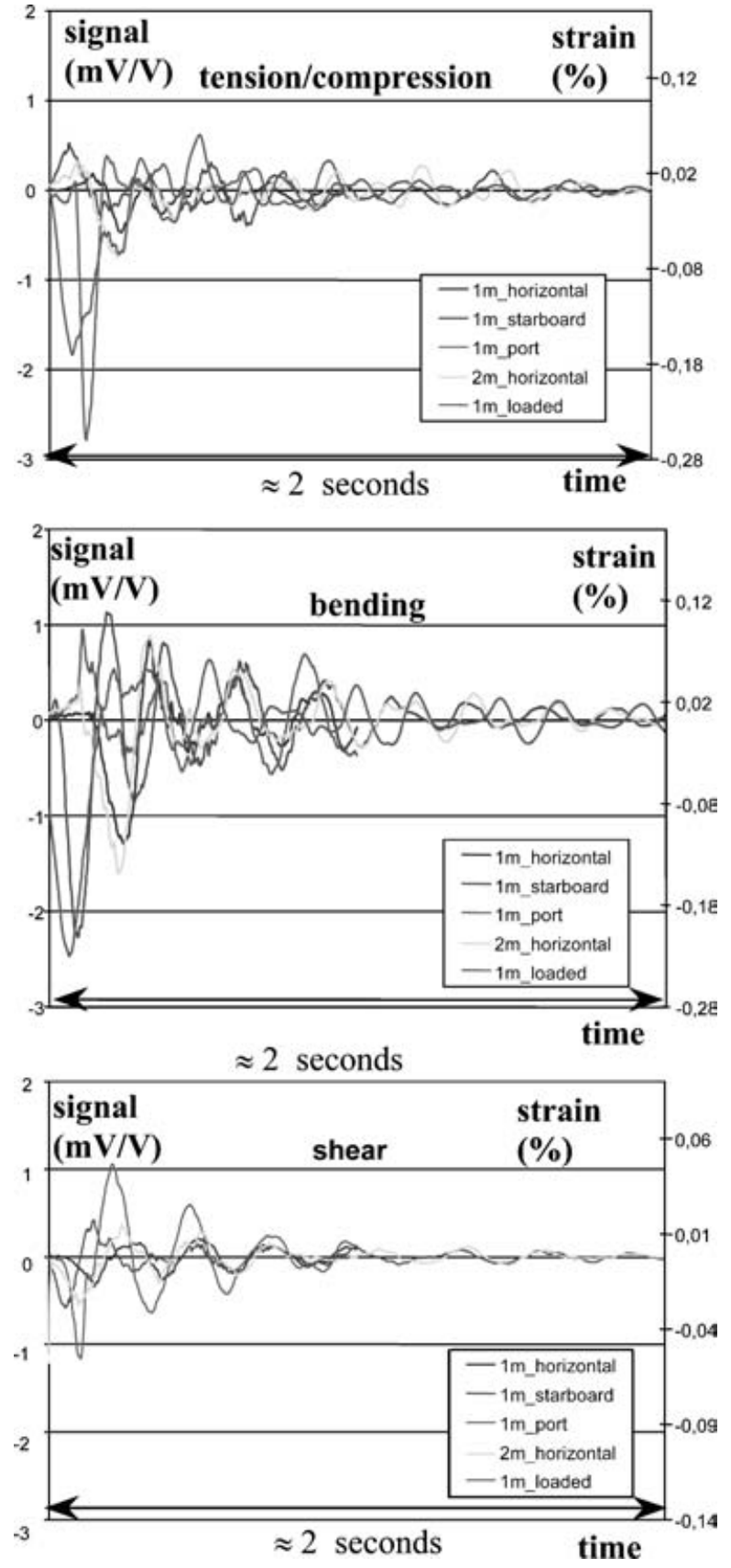

Fig. 8 Examples of recorded data from sensors during drop tests

concentrations near the joint ends, requires very large models, and the strains in these regions are impossible to measure. Nevertheless, some comments may be made.

The data usually available for an adhesive are quasistatic tensile stress-strain plots. An example is shown in Fig. 10 for the filled vinyl ester adhesive used here. The strain at failure is considerably higher than those measured during prototype tests, even taking into account that the strains recorded by each individual loading sensor may be summed in the worst case. Also, prototype measurements from the tension-compression
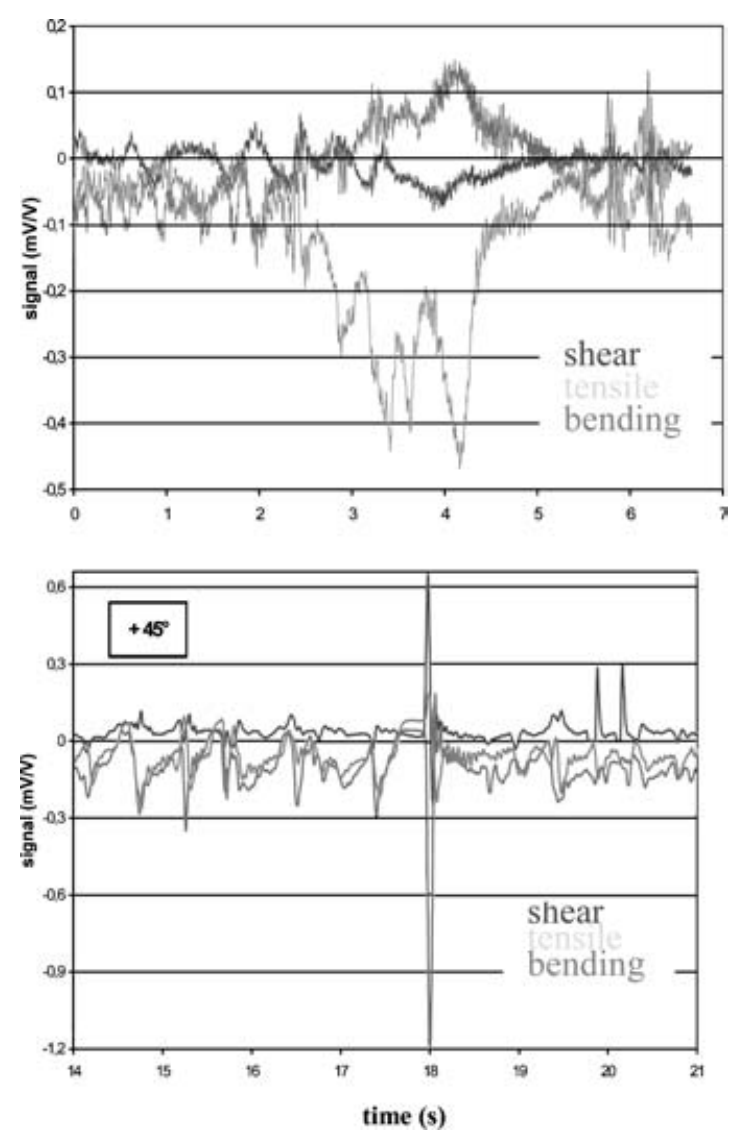

Fig. 9 Sea trial recordings during changes in direction

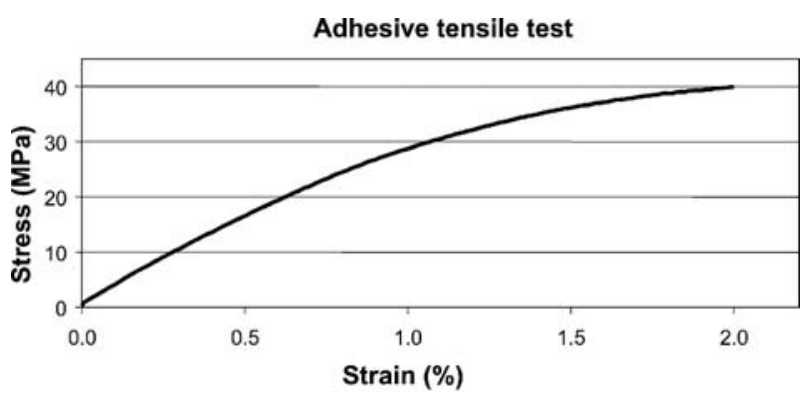

Fig. 10 Tensile stress-strain data, quasi-static test, filled vinyl ester bulk adhesive

sensor indicate that peak values are compressive rather than tensile, and the maximum tensile strain was even lower.

Loading rate effects may affect material properties. The highest strain rates during the prototype tests are around $0.05 \mathrm{~s}^{-1}$. At hot spots (the ends of the joints) these could be even higher. Strain rates in tensile tests are typically 50 times slower than this value, so higher strain rate data may also be needed to assess adhesive performance.

Further studies now underway are focusing on developing design criteria for adhesive connections. 
Particular emphasis is being placed on rate effects and the influence of cyclic loading. Finally, it should be noted that drop tests are now being considered by ISO [13] as a means of qualifying small boat structures.

\section{CONCLUSION}

This study has demonstrated the strong potential for adhesive bonding of bulkhead assemblies in small motorboats. Large savings in assembly time were achieved compared with the traditional overlamination method. Drop tests and sea trials, using specially adapted strain gauge instrumentation, have indicated low strain levels in the adhesive joint, lower during sea trials than during drop tests. The latter may prove to be useful in qualifying the connections, but further tests are needed to validate this. No damage was observed after any of the tests. This suggests that further optimization of the assembly design may be possible, and studies are continuing. Fatigue and ageing studies are also under way, as these will govern long-term performance.

\section{ACKNOWLEDGEMENTS}

The contributions to this project from L. Frimas of Ocqueteau, L. Imbert of Reichold, E. Archambault of Archambault and L. Darold of Fountaine-Pajot are gratefully acknowledged.

\section{REFERENCES}

1 Gibbs and Cox Company Marine Design Manual for Fiberglass Reinforced Plastics, 1960 (McGraw-Hill, New York).

2 Greene, E. Marine Composites (2nd edition), 1998 (Eric Greene Associates, Annapolis, Maryland).
3 Smith, C. S. Design of Marine Structures in Composite Materials, 1990 (Elsevier Applied Science, London).

4 Roy, A. Comportement mécanique en sollicitations monotones et cycliques d'assemblages collés compositecomposite et composite-acier. $\mathrm{PhD}$ thesis, Poitiers University, 1994.

5 Roy, A., Gontcharova-Benard, E., Gacougnolle, J. L. and Davies, P. Hygrothermal effects on failure mechanisms of composites/steel bonded joints. In Time Dependent and Nonlinear Effects in Polymers and Composites, ASTM Special Technical Publication, STP 1357, 2000, pp. 353-71 (ASTM).

6 Huther, M., Roy, A., Gacougnolle, J. L., Goncharova, E. and Davies, P. Adhesive bonding of steel and fibreglass plates for shipbuilding. In Proceedings of 54th Annual Assembly of the International Institute of Welding, Ljubljana, July 2001.

7 Baur, P., Roy, A., Casari, P., Gacougnolle, J. L., Choqueuse, D. and Davies, P. Recherche de la nature des efforts transmis par les liaisons structurales d'un bateau. In Proceedings of Matériaux 2002 Conference, Tours, 2002.

8 Koelbel, Jr, J. G. Structural design for high speed craft. Prof. Boatbuilder, October/November 2000, 31-46.

9 Baley, C. and Cailler, M. Experimental and numerical behaviour of the structure of a 7.7 metre sailing boat at sea. In Proceedings of 3rd IFREMER Conference on Nautical Construction with Composite Materials, Paris, 1992, paper 41, pp. 423-431.

10 Hentinen, M. and Holm, G. Load measurements on the $9.4 \mathrm{~m}$ sailing yacht 'Sail Lab'. In Proceedings of 13th International Symposium on Yacht Design and Yacht Construction, Amsterdam, November 1994.

11 Davies, P., Choqueuse, D. and Roy, A. Fatigue and durability of marine composites. In Fatigue in Composite Materials (Ed. B. Harris), 2003, Ch. 31 (Woodhead Publishers).

12 Hayman, B., Haug, T. and Valsgard, S. Slamming drop tests on a GRP sandwich model. In Proceedings of Sandwich Constructions 2, 9-12 March 1992 (EMAS Publishers, Florida).

13 ISO DIS-12215:2003 Small craft: Hull construction and scantlings. 